\title{
Extreme nouns and maximizers ${ }^{1}$ \\ Melania S. MASIÀ — Universidad Complutense de Madrid
}

\begin{abstract}
Maximizers (completamente 'completely', totalmente 'totally') are degree modifiers restricted to maximum standard adjectives. Spanish adjectives of completeness [ACs] (completo 'complete', total 'total') display a behavior similar to that of their adverbial counterparts when they combine with nouns like idiot. This paper argues that ACs are maximality modifiers of idiot-like nouns, which are defended to be gradable and denote extreme degrees of properties. Establishing a parallelism between adverbs and adjectives of completeness allows us to explore scalarity across categories and the relevance of scale structure in the nominal domain.
\end{abstract}

Keywords: extreme nouns, maximizers, adjectives of completeness, scale structure, nominal gradability.

\section{Introduction}

Maximizers are degree modifiers that compose only with adjectives that use a scale with a maximum (Rotstein and Winter, 2004; Kennedy and McNally, 2005). Some of these modifiers have adjectival forms that combine with nouns. These adnominal forms are thus a valuable way of exploring gradability, and ultimately scale structure, in the nominal domain. In Spanish, the adnominal counterparts of the maximizers completamente 'completely' and totalmente 'totally' appear with nouns like idiot (1).

$$
\begin{aligned}
& \text { Juan es un }\{\text { completo idiota / total desastre }\} \text {. } \\
& \text { Juan is a complete idiot total mess } \\
& \text { 'Juan is a }\{\text { complete idiot / total mess }\} \text {.' }
\end{aligned}
$$

The type of modification completo 'complete' or total 'total' [henceforth, adjectives of completeness or ACs] perform in the noun seems to be degree modification. If it is so, two issues arise. First, nouns like idiot would be gradable. Second, ACs would be degree modifiers sensitive to scale structure. This is in conflict with the common view of nouns as non-gradable, as opposed to adjectives (see Bolinger, 1972; Matushansky, 2002; Morzycki, 2009; Constantinescu, 2011; Sassoon, 2013, a.o.).

This paper argues that ACs are maximality modifiers of idiot-like nouns, which are gradable and denote extreme degrees. I adopt Morzycki's (2012a) analysis of extreme adjectives for

\footnotetext{
${ }^{1}$ This paper is a revised version of a section of my dissertation at the Spanish National Reseach Council and the Universitat Autònoma de Barcelona. I'd like to thank Violeta Demonte, Carme Picallo, and Elena Castroviejo for their helpful comments and discussion. I'm also grateful to four anonymous reviewers and the audiences at the 27 Colloquium on Generative Grammar at the Universidad de Alcalá de Henares, Going Romance 30 at GoetheUniversity in Frankfurt and Sinn und Bedeutung 22 at Universität Potsdam / ZAS Berlin for their feedback. Any remaining errors are my own. The research underlying this work has been partially supported by research project FFI2012-32886 funded by the Spanish MINECO and by scholarship FPU2010-6022 from the Spanish MECD.
} 
Spanish evaluative nouns. Nouns like idiot include a degree argument and a requirement that the value of this argument is above the contextually relevant scale. The degrees that are off the scale constitute a maximum for ACs, and also explain the partial maximizer behavior of these modifiers with idiot-like nouns. This analysis thus unifies the semantics of adverbs and adjectives of completeness and discusses the relevance of scale structure in the nominal domain.

This paper proceeds as follows. $\S 2$ introduces the data about maximizers in the adjectival domain, which is compared to the behavior of ACs when modifying idiot-like nouns in $\S 3$. $\S 4$ is devoted to show that nouns like idiot are gradable and denote extreme degrees and puts forward an analysis of these nouns as extreme predicates. It also discusses their subjectivity. The semantics of ACs is tackled in $\S 5$, which includes a discussion of previous analyses in terms of quantification over properties. Finally, $\S 6$ concludes.

\section{Maximizers in the adjectival domain}

The scales used by gradable adjectives differ in whether they include a maximal and/or a minimum value (Rotstein and Winter, 2004; Kennedy and McNally, 2005). These endpoints are relevant for the calculation of the standard for the predicate. Particularly, the standard of comparison of the adjective is set to the value of the upper or lower bound of the scale whenever there is one. Otherwise, the standard is computed contextually (Kennedy, 2007). From this observation, a typology of adjectives based on their scale structure can be established (2) (Rotstein and Winter, 2004; Kennedy and McNally, 2005).
a. (Totally) open scale adjectives: alto 'tall', ancho 'wide', bello 'beautiful'
b. Lower closed scale adjectives: sucio 'dirty', impuro 'impure', húmedo 'wet'
c. Upper closed scale adjectives: limpio 'clean', seco 'dry', libre 'free'
d. (Totally) closed scale adjectives: abierto 'open', lleno 'full', oscuro 'dark'

Some modifiers are sensitive to the scale structure of the adjectives. For instance, maximizers such as completamente 'completely' or totalmente 'totally' only appear with upper or totally closed scale adjectives (3) (Rotstein and Winter, 2004; Kennedy and McNally, 2005).

$$
\begin{aligned}
& \text { a. completamente }\{\text { seco / oscuro / libre / abierto / limpio / lleno }\} \\
& \text { completely dry dark free open clean full } \\
& \text { b. ?? completamente }\{\text { alta / ancho / bello / impuro / sucio }\} \\
& \text { completely tall wide beautiful impure dirty }
\end{aligned}
$$

Maximizers convey that the referent has a maximal degree of the gradable property denoted by the adjective they modify. Formally, these modifiers set the value of the degree argument of the adjective $G$ to the maximum in its scale $S_{G}$ (4) (Kennedy and McNally, 2005). The restriction on upper and totally closed scale adjectives is accounted for by the function max, which only yields a value if the scale has a defined maximum. 


$$
\llbracket \text { completely } \rrbracket=\lambda G \lambda x . \exists d\left[d=\max \left(S_{G}\right) \wedge G(d)(x)\right]
$$

(Kennedy and McNally, 2005: 369)

Maximizers share a number of properties. First, they entail that the end of the scale has been reached. Consequently, it is contradictory to assert that the referent can have a higher degree of the property (5a) (Kennedy and McNally, 2005). Second, the construction maximizer $G$ is a total construct, in the sense that it has the distribution of an upper-closed scale adjective (Rotstein and Winter, 2004). This is shown by the fact that it is compatible with casi 'almost' (5b). And third, because of the universal quantification in the semantics of the max function, maximizer $G$ accepts exceptive phrases (5c).
a. \#El avión está completamente lleno; hay
un asiento libre en la primera fila. The plane is completely full there.is a seat free in the first row 'The plane is completely full; there is an empty seat in the first row.'
b. El avión está casi completamente lleno. the plane is almost completely full
c. El avión está completamente lleno, excepto un asiento en la primera fila. the plane is completely full except a seat in the first row 'The plane is completely full, except for a seat in the first row.'

In short, maximizers are degree modifiers restricted to adjectives that lexicalize a scale closed (at least) in its upper end. They set the degree of the property denoted by the adjective to its maximum value. Next section is devoted to show the behavior of ACs with idiot-like nouns.

\section{Adjectives of completeness and idiot-like nouns}

As shown in (1), nouns like idiot combine with ACs. The question is whether these modifiers are acting like maximizers when appearing with nouns like idiot. This section compares the properties of ACs modifying these nouns to those of maximizers modifying adjectives.

First, maximizers entail that the end of the scale associated with the predicate has been reached (5a). Consequently, the referent cannot have more of the property denoted by the predicate than it already has. As expected, there is a contradiction in asserting that Juan could be more of an idiot than a complete idiot (6a). However, when Juan's complete idiocy is compared to someone else's, the examples become more acceptable, although not perfect (7a).

\footnotetext{
a. \#Juan es un completo idiota, pero podría serlo más. Juan is a complete idiot but could.3SG be CL more 'Juan is a complete idiot, but he could be more of an idiot.'

b. \#La clase es un absoluto desastre, pero podría serlo más. the class is a absolute mess but could.3SG be CL more 'The class is an absolute mess, but it could be more of a mess.'
} 
(7) a. ?Juan es un completo idiota, pero su hermano lo es más. Juan is a complete idiot but his brother CL is more 'Juan is a complete idiot, but his brother is more of an idiot.'

b. ?La clase es un absoluto desastre, pero la de María lo es más. the class is a absolute mess but the of María CL is more 'The class is an absolute mess, but María's is more of a mess.'

Second, although maximality modifiers are compatible with casi 'almost' (5b), they are ruled out with nouns like idiot (8a). And third, expressions including maximizers accept exceptive phrases (5c). As for idiot-like nouns, exceptives are acceptable, yet slightly degraded (7a).
a. ??Juan es un casi completo idiota.
Juan is a almost complete idiot
'Juan is an almost complete idiot.
b. La clase es un casi absoluto desastre.
the class is a almost absolute mess
'The class is an almost absolute mess.

(9) a. Juan es un completo idiota, menos en su trabajo.

Juan is a complete idiot except in his work

'Juan is a complete idiot, except at work.'

b. La clase es un absoluto desastre, excepto el día del examen.

the class is a absolute mess except the day of the exam

'The class is an absolute mess, except for the day of the exam.'

The data shows that the modification of an idiot-like noun by an AC resembles modification by maximizers, but only partially. The issue is whether an analysis of ACs as maximizers can be maintained. In this paper I defend that it can. In order to show how the data in this section would be explained, the semantics of nouns like idiot is discussed next.

\section{Extreme nouns}

Evaluative nouns like idiot constitute a class of nouns that do not only assign a property to an individual, but also express a value judgment. Several contexts set them apart from nonevaluative nouns. $^{2}$ First, nouns like idiot appear in the first position in qualitative nominal constructions such as the so-called $N$ of an $N$ construction (10) (Bolinger, 1972; Doetjes and Rooryck, 2003; den Dikken, 2006; Villalba and Bartra-Kaufmann, 2010, a.o.). Non-evaluative nouns such as doctor only receive a possessive reading (e.g., 'Juan's doctor').

\footnotetext{
${ }^{2}$ The class of evaluative nouns has been referred to as degree nouns (Bolinger, 1972) or scalar nouns (Matushansky, 2002), and quality nouns (Milner, 1978; Ruwet, 1982). The class includes other nouns (nouns like 'matasanos' quack or ethnic slurs) that I set aside from the discussion (see Masià, forthcoming). For this reason, I mostly refer to the nouns under discussion as 'idiot'-like nouns, and extreme nouns once the analysis is presented.
} 
el \{idiota / genio / desastre / \#médico\} de Juan.

the idiot genius mess doctor of Juan

'that $\{$ idiot / genius / mess / \#doctor $\}$ Juan.'

In addition, in Spanish idiot-like nouns appear in attributive construction with the indefinite articles (11a), in the so-called 'un' enfático ('emphatic un') construction (Portolés, 1994; Fernández Leborans, 1999, a.o.). This contrasts with the behavior of nouns expressing a specific role in society, which appear bare (11b) (Déprez, 2005; de Swart et al., 2007, and references therein).
a. Juan es *(un) $\{$ genio / desastre $\}$.
Juan is a genius mess
'Juan is a genius / mess $\}$.'
b. Juan es (*un) \{médico / secretario $\}$.
Juan is a doctor secretary
'Juan is a $\{$ doctor / secretary $\}$.'

Finally, these nouns can be used in verbless exclamatives (12a) (Vinet, 1991; Hernanz, 2001, a.o.) and independent ones (12b) (Milner, 1978; Suñer Gratacós, 1999; Hernanz, 2001, a.o.).
a. ¡Un \{idiota / genio / desastre / *médico\}, este tío!
a idiot genius mess doctor this guy
'A(n) \{idiot / genius / mess / doctor $\}$, this guy!'
b. $\quad i\{$ Idiota / Genio / Desastre / *Médico $\}$ !
idiot genius mess doctor
' $\{$ Idiot / Genius / Mess / Doctor $\}$ !'

These tests set apart the class of evaluative nouns, of which idiot-like nouns are a subset (for more diagnostics, see Milner, 1978; Ruwet, 1982; Suñer Gratacós, 1999, a.o.). Part of the literature considers that evaluative nouns contain some sort of affective feature that allows them to appear in the above constructions (Milner, 1978; Hernanz, 2001, a.o.; cf. Ruwet, 1982; den Dikken, 2006). Others have argued that the relevant characteristic is a degree argument (Bolinger, 1972; Matushansky, 2002; for discussion, see Constantinescu, 2011).

In this section, I argue that nouns like idiot denote extreme degrees of properties. In order to do so, I first give arguments in favor of a degree analysis of these nouns. Then I compare their properties to those of extreme adjectives. Afterwards, the analysis of idiot-like nouns is provided. Finally, the subjectivity of these nouns is addressed.

\subsection{Idiot-like nouns are gradable}

As just mentioned, some authors take the properties and distribution of evaluative nouns to be linked to the presence of a degree argument (e.g. Bolinger, 1972; Matushansky, 2002). 
Certainly, if some nouns are more likely candidates than others to denote gradable properties, those are evaluative nouns, idiot being the quintessential example (Bolinger, 1972; Morzycki, 2009, 2012b, 2014; de Vries, 2010; cf. Constantinescu, 2011, 2013; Sassoon, 2013). This section provides arguments in favor of nouns like idiot containing a degree argument.

Because of their monotonicity, gradable predicates obtain degree readings when modified by downward-entailing modifiers such as surprisingly or unbelievable (de Vries, 2010, forthcoming, Nouwen, 2011). Nouns like idiot are interpreted in a degree sense when modified by the adnominal versions of those modifiers (13), unlike nouns like doctor. For instance, un idiota increíble 'an incredible idiot' is an idiot to a high degree.

Juan es un $\{$ idiota / ?genio / desastre / \#médico $\}$ increíble.

Juan is a idiot genius mess doctor incredible

'Juan is an incredible \{idiot / genius / mess / doctor $\}$.'

Degree readings are also obtained with size adjectives (Morzycki, 2009; de Vries, 2010; Sassoon, 2013). When a noun like idiot combines with an adjective like enorme 'huge', the interpretation is that the referent has a high degree of the property. Compare this to médico enorme 'huge doctor', where only physical size is available as an interpretation (14).

$$
\begin{aligned}
& \text { Juan es un }\{\text { idiota / genio / desastre / \#médico }\} \text { enorme. } \\
& \text { Juan is a idiot genius mess doctor huge } \\
& \text { 'Juan is a huge }\{\text { idiot / genius / mess / doctor }\} \text {.' }
\end{aligned}
$$

The modification in the examples above is subject to the two properties that characterize degree uses of size adjectives (see Morzycki, 2009). First, the bigness generalization asserts that only adjectives of bigness get degree readings, adjectives of smallness do not. This is true of size adjectives modifying idiot-like nouns. The examples in (15a), although odd, only get a physical size interpretation. Second, the position generalization states that degree readings of size adjectives are only possible in attributive position. That is again the case with idiot-like nouns. Examples (15b) only present a physical size reading.

$$
\begin{aligned}
& \text { a. Juan es un } \text { \# \#pequeño / ??diminuto / ??minúsculo }\} \text { idiota. } \\
& \text { Juan is a small tiny minuscule idiot } \\
& \text { 'Juan is a }\{\text { small / tiny / minuscule }\} \text { idiot.' } \\
& \text { b. \#Este idiota es }\{\text { grande / enorme / gigantesco }\} \text {. } \\
& \text { this idiot is big huge gigantic }
\end{aligned}
$$

Interrogatives provide further evidence for the gradability of idiot-like nouns. In particular, just like gradable adjectives (16a), these nouns appear in degree interrogatives with cómo de in Spanish (16b). Regular nouns like doctor are excluded from this construction. The same happens with quantity exclamatives with cuán 'how' (17). 
a. ¿Cómo de $\{$ alto / amable $\}$ es Juan?

how of tall kind is Juan

'How $\{$ tall / kind $\}$ is Juan?'

b. ¿Cómo de \{idiota / genio / ??médico $\}$ es Juan?

how of idiot genius doctor is Juan

'How much of a(n) \{idiot / genius / doctor $\}$ is Juan?'

(17) ¡Cuán \{alto / amable / genio / desastre / ??médico\} (que) es Juan!

how tall kind genius mess doctor that is Juan

'How $\{$ tall / kind / genius / mess / doctor $\}$ Juan is!'

So far, it seems that nouns like idiot are gradable. At this point, it is reasonable to question what type of scale structure they use (see $\S 2$ ). The data in $\S 3$ already showed that ACs do not have a clear-cut behavior as maximizers when modifying idiot-like nouns, not completely supporting the idea that they use upper-closed scales.

Focusing on data from entailments of the comparative construction (Kennedy and McNally, 2005), nouns like idiot pattern with minimum-standard adjectives in triggering entailments to the unmarked form (18) (Constantinescu, 2011, de Vries, forthcoming). In other words, if someone is more of an idiot than someone else, it is entailed that the first person is an idiot. ${ }^{3}$
a. La habitación está más sucia que la cocina. $\rightarrow$ La habitación está sucia. the room is more dirty than the kitchen the room is dirty
b. ??Juan es más un idiota que Sofía. $\rightarrow$ Juan es un idiota.
Juan is more a idiot than Sofía Juan is a idiot

To sum up, idiot-like nouns are gradable and seem to have minimum standards. That is, having only a small degree of the relevant property (idiocy, messiness, etc.) is enough to qualify as an idiot, a mess, etc. ${ }^{4}$ In the next section I argue that idiot-like nouns denote extreme degrees.

\subsection{Idiot-like nouns denote extreme degrees}

Adjectives such as wonderful or horrible refer to a very high or the highest degree of a property (Cruse, 1986) and, in this sense, are close to superlatives. This class of adjectives that includes extremeness in their lexical semantics are often referred to as extreme adjectives (Cruse, 1986; Paradis, 1997, 2001; Morzycki, 2012a). In this section, I argue that nouns like idiot also denote extreme degrees of properties (see also Constantinescu, 2011; Morzycki, 2012a, 2014).

\footnotetext{
${ }^{3}$ Although nouns like idiot in comparative constructions in Spanish are somewhat degraded (especially if the determiner appears), speakers find that the entailments still come through.

${ }^{4}$ De Vries argues that this is related to the fact that these nouns do not have a prototype that may constitute an upper bound (for details, see de Vries, 2010, forthcoming).
} 
Intuitively, for someone to qualify as an idiot, just some degree of dumbness is not enough, the individual needs to be remarkably dumb.

To begin with, some of the contexts in $\S 4$ allow adjectives in the relevant positions. However, being gradable is not enough for adjectives to appear in these constructions. Rather, they need to denote extreme degrees. For example, non-extreme adjectives such as tall are excluded in the $N$ of a $N$ construction (19a) (cf. (10)) (Constantinescu, 2011). The same is true of verbless or independent exclamatives (19b) (cf. (12a)) (Vinet, 1991; Hernanz, 2001, a.o.).

$$
\begin{aligned}
& \text { a. el }\{\text { ??alto / ??amable / horrible / magnífico }\} \text { de Juan } \\
& \text { the tall nice horrible great of Juan } \\
& \text { 'that }\{\text { tall / nice / horrible / great }\} \text { Juan.' } \\
& \text { b. i }\{\text { ??Alto / ??Amable / Horrible / Magnífico }\} \text { (, este chico)! } \\
& \text { tall nice horrible great this guy } \\
& \text { ' }\{\text { Tall / Nice / Horrible / Great }\} \text { (, this guy)!' }
\end{aligned}
$$

In addition, extreme predicates display several specific properties. First, they have their own specialized degree modifiers. While modifiers such as directamente 'downright' do not appear with non-extreme adjectives, regular degree modifiers like bastante 'fairly' do not occur with extreme adjectives (20) (Cruse, 1986; Paradis, 1997; Hernanz, 2001; Morzycki, 2012a, a.o.). In the same way, nouns like idiot combine with equivalent adnominal modifiers, which are impossible in their degree reading with non-gradable nouns such as doctor (21).

$$
\begin{aligned}
& \text { a. Juan es directamente } \text { maravilloso / ??alto }\} \text {. } \\
& \text { Juan is downright wonderful tall } \\
& \text { b. Juan es bastante }\{\text { ??maravilloso / alto }\} \text {. } \\
& \text { Juan is fairly wonderful tall }
\end{aligned}
$$

a. Juan es un valiente $\{$ idiota / genio / \#médico $\}$.

Juan is a brave idiot genius doctor

'Juan is a downright \{idiot / ??doctor $\}$.'

b. La clase es una soberana $\{$ maravilla / *actividad . the class is a supreme wonder activity 'The class is a full-on $\{$ wonder / *activity\}.'

Second, extreme predicates are somewhat unnatural in comparatives, with different degrees of acceptability among speakers, but more acceptable in equatives (22) (Cruse, 1986; Paradis, 1997; Morzycki, 2012a). Idiot-like nouns are also slightly more degraded in comparative than in equative structures (23).

a. Juan es más \{??maravilloso / ??horrible / alto $\}$ que Sofía. Juan is more wonderful horrible tall than Sofía 
b. Juan es tan $\{$ maravilloso / horrible / alto $\}$ como Sofía.

Juan is as wonderful horrible tall as Sofía
a. ??Juan es más (un) genio que Sofía.
Juan is more a genius than Sofía
'Juan is more of a genius than Sofía.'
b. ?Juan es tan genio como Sofía.
Juan is as genius as Sofía
'Juan is as much of a genius as Sofía.'

Third, extreme predicates can be intensified through prosodic prominence (24a) (Cruse, 1986; Bolinger, 1972; Morzycki, 2012a). Idiot-like nouns behave accordingly (24b).

$$
\begin{aligned}
& \text { a. Kevin Spacey is }\{\text { fantaaaastic / ??goooooooooood }\} \text { ! } \\
& \text { b. Juan es un }\{\text { idioooota / ??méeeeedico }\} \text {. } \\
& \text { Juan is a idiot doctor }
\end{aligned}
$$

(Morzycki, 2012a)

In short, nouns like idiot denote extreme degrees of properties. The tests in this section showed that they behave like extreme adjectives. It can be thus concluded that these nouns encode extremeness in their lexical semantics. This idea is implemented in the next section.

\subsubsection{Analysis}

In order to account for the semantics of nouns like idiot, I adopt Morzycki's (2012a) analysis of extreme adjectives. The basic intuition is that different subsets of scales are relevant in different contexts, and extremeness consists of going off the relevant scale, to a point where no further distinctions between degrees are made (Morzycki, 2012a). For instance, in order to qualify as an idiot, someone has to be dumb to a degree above any expectation, off the relevant scale for the adjective $d u m b$, in a zone of indifference between degrees of dumbness.

This idea connects with contextual domain restriction. In the same way quantifiers are contextually restricted (e.g. von Fintel, 1994), degree quantification is also subject to contextual variation in its domains (e.g. Zanuttini and Portner, 2003). Contextual domain restriction is thus introduced in the denotation of ordinary adjectives (Morzycki, 2012a). The semantics for $d u m b$ in (25a) includes the restriction that the degree $d$ has to be in the salient set of degrees in the contextual scale $C$. In the absence of degree morphology, the null morpheme POS saturates the degree argument and establishes the requirement that the degree exceeds the standard (25b).

$$
\begin{array}{ll}
\text { a. } & \llbracket d u m b \rrbracket=\lambda d \lambda x[d \in C \wedge \operatorname{dumb}(d)(x)] \\
\text { b. } & \llbracket \operatorname{POS} d u m b_{C} \rrbracket=\lambda x . \exists d\left[d \in C \wedge \operatorname{dumb}(d)(x) \wedge d \succeq \mathbf{s t n d}\left(\llbracket d u m b_{C} \rrbracket\right)\right]
\end{array}
$$

(Morzycki, 2012a) 
Extreme predicates exceed the contextually-provided set of degrees. This is reflected in the condition that their degree $d$ of the property is greater than the maximal degree in the contextual scale $C$ (Morzycki, 2012a). Extending the analysis to nouns like idiot, their denotation would be as in (26).

$$
\begin{array}{ll}
\text { a. } & \llbracket \text { idiota }_{C} \rrbracket=\lambda d \lambda x[d>\max (C) \wedge \operatorname{dumb}(d)(x)] \\
\text { b. } & \llbracket \text { genio }_{C} \rrbracket=\lambda x \lambda d[d>\max (C) \wedge \operatorname{smart}(d)(x)]
\end{array}
$$

Under this analysis, like gradable adjectives in a degree-based framework, nouns like idiot have degree arguments and are lexically associated with scales. Just like in the case of adjectives, a degree morpheme is necessary to get to a property of individuals. If no overt degree word is present, I assume a null POS morpheme saturates the degree argument (Morzycki, 2009). ${ }^{5}$ According to (27), an individual is an idiot if, and only if, she is dumb to a degree $d$ that exceeds the standard for the predicate in $C$ and that is greater than the highest salient degree of dumbness in $C$. In this case, the standard and the domain restriction interact: for the standard to be relevant, it must be beyond the perspective scale.

$$
\begin{array}{ll}
\text { a. } & \llbracket \operatorname{POS} \text { idiota }_{C} \rrbracket=\lambda x . \exists d\left[d>\mathbf{m a x}(C) \wedge \operatorname{dumb}(d)(x) \wedge d \succeq \mathbf{s t n d}\left(\llbracket \text { idiota }_{C} \rrbracket\right)\right] \\
\text { b. } & \llbracket \operatorname{POS} \text { genius }_{C} \rrbracket=\lambda x . \exists d\left[d>\mathbf{m a x}(C) \wedge \mathbf{s m a r t}(d)(x) \wedge d \succeq \mathbf{s t n d}\left(\llbracket \text { genius }_{C} \rrbracket\right)\right]
\end{array}
$$

Nouns like idiot are fundamentally adjective-like, as manifested in their similar distribution in inversion constructions (10), (19a), exclamatives (12), (19b), and questions (16). The denotations in (27) reflect this adjectival condition of these nouns not only by providing them with gradable semantics, but also by using adjectival measure functions. Besides this, by including the measure function of the non-extreme or more neutral adjective, the denotation of extreme nouns accounts for the entailments to the non-extreme form (28). Any individual dumb enough to be an idiot must have a degree of dumbness beyond $C$; by monotonicity, any individual dumb to that degree is dumb to all the degrees below, including the standard for $d u m b$.

$$
\begin{aligned}
& \text { a. Juan es un idiota. } \rightarrow \text { Juan es tonto. } \\
& \text { Juan is a idiot Juan is dumb } \\
& \text { b. Juan es un genio. } \rightarrow \text { Juan es listo. } \\
& \text { Juan is a genius Juan is smart }
\end{aligned}
$$

Hernanz (2001) argues that evaluative expressions have a $w h$-feature that explains their occurrence in inversion constructions, exclamatives, and other wh-like behavior. In the analysis of nouns like idiot put forward here, they include a widening in the domain of degrees. In particular, these nouns refer to degrees that exceed the maximal degree in the salient set of degrees. This connects with Zanuttini and Portner's (2003) analysis of wh-exclamatives, according to which exclamatives involve domain widening by the combination of a wh-word and a factive

\footnotetext{
${ }^{5}$ Looking ahead, ACs are argued to be overt degree morphemes in the next section. Morzycki (2009) actually already considers ACs to be adnominal degree morphemes, but his analysis differs from ours in that his gradable nouns do not denote extreme degrees.
} 
operator. Thus, there seems to be a connection between $w h$-behavior and evaluativity that could be made explicit by our analysis.

One way of doing this could be to link extremeness to mirativity (DeLancey, 1997; for analyses of exclamatives as mirative constructions, see Michaelis, 2001; Castroviejo Miró, 2006), and, ultimately, to expressivity (see Martin, 2007 for extreme adjetives). More specifically, the fact that the individual has a property to an unexpectedly high degree is accompanied by an emotion (surprise, but also other emotions like annoyance) by part of the speaker. This emotional attitude arises from the truth-conditional meaning of evaluative nouns and constitutes their expressive meaning. ${ }^{6}$ For instance, if someone is smart to so extreme a degree to qualify as a genius, it causes in the speaker an emotional attitude of surprise or admiration towards that individual.

To summarize, nouns like idiot have been given a denotation that involves extreme degrees, following the analysis for extreme adjectives in Morzycki (2012a). In particular, they are gradable properties of individuals, with the requirement that the degree of the property exceed the contextually salient set of degrees. Next section discusses subjectivity of extreme nouns.

\subsection{Consequences of the analysis: subjectivity}

Before proceeding to the analysis of ACs, let me briefly discuss one consequence of the analysis above, which helps clarify the connection between being extreme and being evaluative. Subjective predicates are predicates whose truth is relativized to the perspective of a judge (Lasersohn, 2005; Stephenson, 2007; Bylinina, 2014, a.o.). For instance, a sentence like Roller-coasters are fun may be true for one speaker but false for another, and both can be right at the same time.

Extreme nouns pass the tests for subjectivity. They can appear as the complement of subjective attitude verbs (29a) Sæbø, 2009 and they give rise to faultless disagreement (29b) (Lasersohn, 2005; Stephenson, 2007). Regarding the latter, speaker B's does not constitute a contradiction, because both speakers can be right.

a. Juan me parece $\{$ divertido / un idiota / un genio / un desastre $\}$.

Juan DAT.1SG find funny a idiot a genius a mess

'I find Juan \{funny / an idiot / a genius / a mess \}.'

b. A: Juan es \{divertido / un idiota /un genio / un desastre\}.

'Juan is $\{$ funny / an idiot / a genius / a mess $\}$.'

B: No, no lo es.

'No, he's not.'

FAULTLESS DISAGREEMENT

Adjectives can be subjective in two ways (Bylinina, 2014; Kennedy, 2016). They can be subjective with respect to the threshold for its application or with respect to the ordering of the

\footnotetext{
${ }^{6}$ In this paper, I leave the expressive component of idiot-like nouns aside, but see Masià (2017b) for an analysis.
} 
individuals in their extension. For instance, fun is subjective regarding its standard: two speakers may disagree on whether roller-coasters are above the standard for fun because one places the standard higher than the other. In addition, the ordering of the set \{roller-coasters, climbing, reading $\}$ for fun may be $\langle$ roller-coasters, climbing, reading $\rangle$ for one speaker, but $\langle$ reading, roller-coasters, climbing ) for another. Since idiot-like nouns have been argued to use adjectival scales from evaluative adjectives in their semantics (26) and these adjectives are subjective in the two ways (Bylinina, 2014; Kennedy, 2016), extreme nouns are expected to be two-way subjective as well.

The tests in (29), using the positive form of the adjective and a positive construction for the noun, show that extreme nouns are subjective with respect to their standard. Subjectivity with respect to their ordering is detected by the acceptability of the comparative form in the diagnostics above. Since extreme nouns in the comparative form are slightly degraded, so are the examples in (30) including them. Nevertheless, they are not ruled out with subjective attitude verbs (30a) and they give rise to faultless disagreement (30b).
a. Juan me parece más \{divertido / ?genio / ?desastre\} que Sofía. Juan DAT.1SG find more funny genius mess than Sofía 'I find Juan \{funnier / more of a genius / more of a mess\} than Sofía.'
b. A: Juan es más \{divertido / ?genio / ?desastre $\}$ que Sofía. 'Juan is \{funnier / more of a genius / more of a mess $\}$ than Sofía.'
B: No, no lo es. 'No, he's not.'
FAULTLESS DISAGREEMENT

Just like evaluative adjectives, extreme nouns seem to be subjective in two ways. I suggest that this fact can be related to the presence of adjectival measure functions in the lexical semantics of nouns like idiot in the analysis put forward in $\S 4.2 .1$. Next section presents the analysis of ACs as adnominal maximizers.

\section{Back to adjectives of completeness}

\subsection{Adjectives of completeness are maximizers}

Since idiot-like nouns denote gradable properties, an analysis of ACs as degree modifiers is sustained. However, there are some difficulties. Maximizers are sensitive to scale maximums, but the nouns under discussion seem to use scales with no upper-bound ( $\S 4.1)$. Therefore, either the maximum for ACs must be provided by something other than a bound in a lexical scale, or, alternatively, ACs need to be analyzed as non-maximizers. In this section I argue for the first option, showing that the special behavior of ACs with nouns like idiot can be derived from the particularities of the extremeness the latter include in their lexical meaning.

Paradis (1997) observes that extreme adjectives have an inherent superlativity, and, in this sense, they represent the ultimate point of a scale. She argues that maximizers combine with adjectives such as wonderful to reinforce their extremeness. In the approach to extremeness 
adopted in the previous section (Morzycki, 2012a), the contextually provided scale contributes a sort of maximum: the degrees above it. Since these degrees are undifferentiated, they can be thought of as a single one. For instance, for a noun like idiot, it is not the case that there is a ceiling of idiocy, but rather that, above certain degree, we do not introduce any distinction between the degrees of idiocy of the individuals. In a sense, that set of indistinct degrees acts as a maximum (see Morzycki, 2012a: 606).

If the degrees above the salient scale form a kind of boundary, this may constitute an appropriate maximum for maximizers. I argue that it is in fact a degree that can be returned by the max function in the semantics of maximality modifiers. ACs can thus be analyzed as maximizers (31) (see also Morzycki, 2009).

$$
\llbracket A C \rrbracket=\lambda G_{\langle d,\langle e, t\rangle\rangle} \lambda x . \exists d\left[d=\max \left(S_{G}\right) \wedge G(d)(x)\right]
$$

The composition of an AC with an extreme noun is then as in (32a). The AC saturates the degree argument of the noun and sets its value to the maximum of the scale. Two restrictions apply on the degree $d$. It must be above the relevant set of degrees in $C$ and it must be the maximum (of the degrees off the scale lexicalized by $d u m b$ ). ${ }^{7}$ According to this semantics, Juan is a complete idiot if, and only if, he has a degree of dumbness above the salient set of degrees in the context (32b).

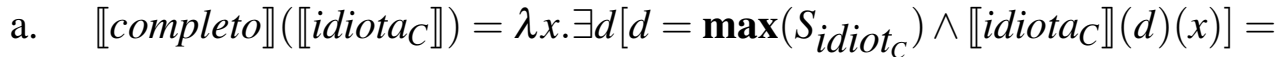

$$
\begin{aligned}
& =\lambda x . \exists d\left[d=\max \left(S_{\text {idiot }_{C}}\right) \wedge d>\max (C) \wedge \operatorname{dumb}(d)(x)\right] \\
& \text { b. } \quad \llbracket J u a n \text { es un completo idiota } \rrbracket= \\
& =\exists d\left[d=\max \left(S_{\text {idiot }_{C}}\right) \wedge d>\max (C) \wedge \operatorname{dumb}(d)(\text { Juan })\right]
\end{aligned}
$$

The fact that no distinction is made among the degrees above the relevant set of degrees in $C$ has the consequence of blurring the difference between the unmodified and the modified extreme noun. Put differently, there is not a sharp distinction between being an idiot and being a complete idiot. This does not mean that ACs have no effect. By means of the maximality function, the degree of idiocy of complete idiot is always higher than that of idiot. But due to the fact that these degrees do not have exact, determinate values, the contrast is fuzzy. This may explain the oddness of the sentences in (33).

a. ??Juan es un idiota, pero no un completo idiota.

Juan is a idiot but NEG a complete idiot

'Juan is an idiot, but not a complete idiot.'

\footnotetext{
${ }^{7}$ This analysis of ACs is different from considering them extreme degree modifiers in Morzycki's (2012a)'s terms. Under his analysis, modifiers such as downright widen the domain of degrees to accommodate a new standard for the predicate. Roughly, the standard for downright gigantic is situated above the already expanded domain for big in the semantics of gigantic. In my analysis, ACs target the widened set of degrees used by extreme nouns, but do not have a widening effect themselves. This analysis is compatible with other degree uses of ACs (see $\S 2$; see also Masià, 2017a, 2018).
} 
b. ??La clase es un desastre, pero no un absoluto desastre. the class is a mess but NEG a absolute mess 'the class is a mess, but not an absolute mess.'

\subsection{Explaining the data}

We can now explain the nonmaximizer behavior of ACs described in $\S 3$. Regarding the entailment that the end of the scale has been reached, recall that sentences with ACs and extreme nouns result in a contradiction when the degree of the property of the same individual is being compared (6a), but not when the comparison is drawn between the degrees of two different individuals (7a). For instance, saying that Juan is a complete idiot, but he could be more of an idiot is as contradictory as saying that a plane is completely full, but could be fuller (5a). By contrast, there is not so strong a conflict when asserting that Juan is a complete idiot, but someone else exceeds his degree of idiocy.

If Juan is a complete idiot, he has a maximal amount of idiocy, although the particular corresponding degree cannot be pinpointed, due to the fact that that degree is beyond the salient scale. It feels unnatural to recalculate that maximum when considering the same individual (unless some new facts are learned about Juan) because the speaker is contradicting her own property assignment. However, given that the maximum is undetermined, the speaker can situate it at a higher value than she originally did if the context changes (for instance, she meets Juan's brother). In fact, note that the sentences improve if todavía 'even' is added (34).

(34) Juan es un completo idiota, pero su hermano lo es todavía más.

Juan is a complete idiot but his brother CL is even more

'Juan is a complete idiot, but his brother is even more of an idiot than him.'

As for the incompatibility with casi 'almost' (8a), I suggest that it has to do with this expression presupposing an identifiable maximum. Almost targets a value that is close to the maximum, but has not reached it. If the maximum for, say, being an idiot cannot be singled out, the expression un casi completo idiota 'an almost complete idiot' would not return a concrete value either, and the difference between being a complete idiot and being an almost complete idiot would be trivial (see also Paradis, 1997: §3.3.3).

Exceptive phrases were fairly acceptable with ACs and extreme nouns (9a), as expected from a total construct. The presence of an AC usually has the side effect of decreasing the amount of imprecision allowed in the context. As a consequence, the number of exceptions is reduced, making exceptives slightly less felicitous than in the sentences without the maximizer.

Coming back to the scale structure of extreme nouns, the data in (18) pointed to them having a minimum standard. Although that still holds, their combination with ACs and the maximality interpretation that the latter receive provides evidence for them having a maximum as well. As 
mentioned above, this is not a conventional maximum, but one made of degrees off the relevant contextual scale.

In short, ACs are maximizers of extreme nouns. They set the degree of the property denoted by these nouns to its maximum value. However, since those degrees exceed the contextually provided scale and no distinctions are made among them, the combination of ACs and extreme nouns presents a mixed behavior with respect to maximality. In the next section, I discuss a couple of alternative analyses.

\subsection{Alternative analyses}

Previous analyses of ACs take them to universally quantify over dimensions associated with the noun. This section reviews a non-degree and a degree proposal along these lines and shows that they are not sufficient to capture the distribution of ACs with extreme nouns.

Constantinescu (2011) argues that ACs in their intensifying use with idiot-like nouns signal the extent to which the property denoted by the noun holds of the object in question. She puts forward that ACs apply to the characteristic function included in the meaning of the noun (e.g. Bouchard, 2002; Demonte, 2008) and assert that the properties displayed by the individual match those associated with the noun, in the speaker's opinion. However, the noun's defining criteria does not have to be exhaustively satisfied, as shown by the nonmaximal behavior of ACs in these uses (see $\S 3$ ), it is enough if the relevant properties are clearly manifested in a salient way. For instance, for a workshop to be a complete failure, it may be enough if it is a failure in an aspect especially relevant to the speaker (e.g., quality of the talks), even if it is not in other less salient respects (e.g., quality of the coffee).

The idea that ACs indicate that the referent fully matches the definition of the noun is problematic. All nouns have a set of criteria an individual must satisfy to qualify as them. However, this reading of ACs is only available for extreme nouns. If the role of ACs were to assert that the noun is right for the individual, they would be expected to have this function with all nouns. For instance, the examples in (35) would be predicted to convey that those particular instances deserved to be referred to as a novel and a conference, respectively, but that is not the case.

$$
\begin{aligned}
& \text { ?Esta es una completa }\{\text { novela / conferencia\}. } \\
& \text { this is a complete novel workshop } \\
& \text { 'This is a comprehensive }\{\text { novel / workshop }\} \text {.' }
\end{aligned}
$$

The intuition that ACs indicate that the referent is an $\mathrm{N}$ in all the relevant dimensions associated with the noun can be recast in a degree-based framework. Sassoon $(2013,2017)$ argues that nouns like idiot are similar to adjectives in their occurrence with with respect to phrases (36).

Dan is an idiot $\{$ with respect to money / in every respect $\}$.

(Sassoon, 2013) 
Relatedly, de Vries (2010, forthcoming) claims that idiot-like nouns are gradable and use open scales (see also Morzycki, 2009). ACs are analyzed as modifiers that assert that the individual has every dimension associated with the noun. For instance, a total nerd would be someone who is nerdy with respect to his looks, social skills, intelligence, hobbies, etc. This predicts that nouns modified by ACs do not accept with respect to-phrases, but this is not borne out (37). Someone can be a total idiot or a complete mess only with respect to one dimension.
a. Era un idiota total en cuanto a calorías, alimentos y cosas de esas. ${ }^{8}$ was a idiot total with regard to calories food and things of those 'I was a total idiot regarding calories, food, and things like that.'
b. Soy un completo desastre con respecto a las lanas y los proyectos. ${ }^{9}$ am a complete mess with respect to the yarns and the projects 'I'm a complete mess with respect to yarn and (DIY) projects.'

This said, it is not completely clear to me that all the with respect to phrases in (36), (37) target actual dimensions of the noun. What properties make someone an idiot? Someone may consider that not knowing how to manage money makes you an idiot, but that is certainly neither a necessary nor a sufficient condition to qualify as one. Rather, it seems one of the many ways in which someone can be an idiot. Consider a noun like smoker instead, which has clear(er) dimensions (Morzycki, 2012b). A smoker is someone who smokes a certain amount of cigarettes with a specific frequency. Some degree in both dimensions is necessary for someone to qualify as a smoker. A complete smoker would be someone who has a high degree in both dimensions. However, ACs are not felicitous with this noun (38).

\section{??Juan es un completo fumador. \\ Juan is a complete smoker}

Morzycki (2012b) argues that nouns like idiot are only associated with one dimension (e.g., idiocy). ACs are analyzed as modifiers that assert that the measurement of the individual along the dimension associated with the noun is large (39). For instance, Clyde is an utter idiot if, and only if, his measure along the unique dimension associated with idiot, idiocy, is large. ACs include the requirement that the noun have only one dimension (represented by the iota operator), accounting thus for their distribution.

$$
\llbracket u t t e r \rrbracket^{c}=\lambda f_{\langle e, t\rangle} \lambda x . \operatorname{large} \mathbf{e}_{c}(\mu(\imath D[D \in \operatorname{dimensions}(f)])(x))
$$

The analysis put forward here resembles Morzycki's (2012b) in that it assumes that the only dimension of measurement relevant for extreme nouns is the one provided by the measure function of their related adjectives. However, we have considered nouns like idiot to be gradable (extreme, in particular) (cf. Morzycki, 2009), and have argued that ACs can be analyzed as maximality modifiers, unifying them to the analysis of their adverbial counterparts.

\footnotetext{
${ }^{8}$ http://1medbio.blogspot.com.es/2012/09/medicina-biologica-dr-german-duque_22.html

${ }^{9}$ http://www.waselwasel.com/crisis-tejeril/
} 
In short, an analysis of ACs as quantifying over the characteristics or dimensions associated with the noun does not fully cover the data. For this reason, ACs are better understood in terms of maximality modifiers of extreme nouns.

\section{Conclusion}

This paper has argued that ACs are maximality modifiers of nouns like idiot. The latter have been analyzed as extreme predicates. That is, idiot-like nouns are gradable and denote extreme degrees. This means that their degree arguments have values above the relevant scale in the context. ACs modifying extreme nouns behave only partially as maximizers because of the type of maximum those nouns provide. In particular, the set of degrees off the relevant scale constitute a sort of maximum, but the degrees in that interval are undifferentiated to one another.

Providing an analysis of ACs as maximizers has reinforced the parallelism between adverbial and adjectival modification and unraveled the ways in which nouns can be gradable and the significance of scale structure in their semantics. Nevertheless, gradability in the nominal domain is still a controversial issue and its connection to evaluativity and subjectivity is not fully understood. Exploring other instances of evaluative nouns, such as expressive variants (quack as the variant of doctor), ethnic slurs or nouns formed by an affective suffix (e.g., Spanish politicastro 'politician.PEJ'), their contribution to the expressive dimension of meaning (Potts, 2005; Gutzmann, 2013), and their combination with adnominal degree modifiers may shed light in that direction.

\section{References}

Bolinger, D. (1972). Degree Words. The Hague: Mouton.

Bouchard, D. (2002). Adjectives, Number and Interfaces: Why Languages Vary. Amsterdam: Elsevier.

Bylinina, L. (2014). The Grammar of Standards: Judge-Dependence, Purpose-Relativity, and Comparison Classes in Degree Constructions. Ph. D. thesis, U. Utrecht.

Castroviejo Miró, E. (2006). Wh-Exclamatives in Catalan. Ph. D. thesis, U. Barcelona.

Constantinescu, C. (2011). Gradability in the Nominal Domain. Ph. D. thesis, U. Leiden.

Constantinescu, C. (2013). Big eaters and real idiots: Evidence for adnominal degree modification? In E. Chemla, V. Homer, and G. Winterstein (Eds.), Proceedings of Sinn und Bedeutung 17, pp. 183-200.

Cruse, D. A. (1986). Lexical Semantics. Cambridge: Cambridge University Press.

DeLancey, S. (1997). Mirativity: The grammatical marking of unexpected information. Linguistic Typology 1(1), 33-52.

Demonte, V. (2008). Meaning-form correlations and adjective position in spanish. In L. McNally and C. Kennedy (Eds.), Adjectives and Adverbs: Syntax, Semantics, and Discourse, pp. 71-100. Oxford: Oxford University Press.

Déprez, V. (2005). Morphological number, semantic number and bare nouns. Lingua 115(6), $857-883$. 
den Dikken, M. (2006). Relators and Linkers: The Syntax of Predication, Predicate Inversion, and Copulas. Cambridge, MA: MIT Press.

Doetjes, J. and J. Rooryck (2003). Generalizing over qualitative and quantitative constructions. In M. Coene and Y. D'hulst (Eds.), From NP to DP, Volume 1, pp. 277-296. Amsterdam: John Benjamins.

Fernández Leborans, M. J. (1999). La predicación: las oraciones copulativas. In I. Bosque and V. Demonte (Eds.), Gramática descriptiva de la lengua española, Volume II, pp. 2357-2460. Madrid: Espasa Calpe.

von Fintel, K. (1994). Restrictions on Quantifier Domains. Ph. D. thesis, U. Massachusetts.

Gutzmann, D. (2013). Expressives and beyond: An introduction to varieties of conventional non-truth-conditional meaning. In D. Gutzmann and H.-M. Gärtner (Eds.), Expressives and Beyond. Explorations of Conventional Non-Truth-Conditional Meaning, pp. 1-58. Leiden: Brill.

Hernanz, M. L. (2001). ¡En bonito lío me he metido! Notas sobre la afectividad en español. Moenia. Revista Lucense de Lingüística y Literatura 7, 93-109.

Kennedy, C. (2007). Vagueness and grammar: The semantics of relative and absolute gradable adjectives. Linguistics and Philosophy 30(1), 1-45.

Kennedy, C. (2016). Two kinds of subjectivity. In C. Meier and J. Van Wijnbergen-Huitink (Eds.), Subjective Meaning: Alternatives to Relativism, pp. 105-126. Berlin: De Gruyter.

Kennedy, C. and L. McNally (2005). Scale structure and the semantic typology of gradable predicates. Language 81(2), 345-381.

Lasersohn, P. (2005). Context dependence, disagreement, and predicates of personal taste. Linguistics and Philosophy 28(6), 643-686.

Martin, F. (2007). Prédicats superlatifs à l'impératif. Travaux de linguistique 55(2), 119-130.

Masià, M. S. A typology of evaluative nouns. In Romance Languages and Linguistic Theory 2016. Selected papers from 'Going Romance' Frankfurt 2016. Amsterdam: John Benjamins.

Masià, M. S. (2017a). Adjectives of completeness as maximizers of event nominalizations. Borealis: An International Journal of Hispanic Linguistics 6(2), 125-154.

Masià, M. S. (2017b). Adverbial adjectives and nominal scalarity. Ph. D. thesis, U. Autònoma de Barcelona.

Masià, M. S. (2018). From completely free to complete freedom. Spanish adjectives of completeness as maximizers of property concept nouns. In J. Berns, H. Jacobs, and D. Nouveau (Eds.), Romance Languages and Linguistic Theory 13. Selected papers from Going Romance 29, Nijmegen. Amsterdam: John Benjamins.

Matushansky, O. (2002). Tipping the scales: The syntax of scalarity in the complement of Seem. Syntax 5(3), 219-276.

Michaelis, L. (2001). Exclamative constructions. In M. Haspelmath (Ed.), Language Typology and Language Universals: An International Handbook, Volume 2, pp. 1038-1050. Berlin: De Gruyter.

Milner, J.-C. (1978). De la syntaxe a l'interprétation : quantités, insultes, exclamations. Paris: Éditions du Seuil.

Morzycki, M. (2009). Degree modification of gradable nouns: Size adjectives and adnominal degree morphemes. Natural Language Semantics 17(2), 175-203. 
Morzycki, M. (2012a). Adjectival extremeness: Degree modification and contextually restricted scales. Natural Language \& Linguistic Theory 30(2), 567-609.

Morzycki, M. (2012b). The several faces of adnominal degree modification. In J. Choi, E. A. Hogue, J. Punske, D. Tat, J. Schertz, and A. Trueman (Eds.), Proceedings of the 29th West Coast Conference on Formal Linguistics, Somerville, MA, pp. 187-195. Cascadilla Press.

Morzycki, M. (2014). Where does nominal gradability come from? misgivings, second thoughts, regrets, and the hope of redemption. Paper presented at U. Massachusetts.

Nouwen, R. (2011). Degree modifiers and monotonicity. In P. Égré and N. Klinedinst (Eds.), Vagueness and Language Use, pp. 146-164. Basingstoke: Palgrave Macmillan.

Paradis, C. (1997). Degree Modifiers of Adjectives in Spoken British English. Lund: Lund University Press.

Paradis, C. (2001). Adjectives and boundedness. Cognitive Linguistics 12, 47-64.

Portolés, J. (1994). La metáfora y la lingüística: los atributos metafóricos con un enfático. In V. Demonte (Ed.), Gramática del español, pp. 531-556. México: Colegio de México.

Potts, C. (2005). The Logic of Conventional Implicatures. Oxford: Oxford University Press.

Rotstein, C. and Y. Winter (2004). Total adjectives vs. partial adjectives: Scale structure and higher-order modifiers. Natural Language Semantics 12(3), 259-288.

Ruwet, N. (1982). Grammaire des insultes et autres études. Paris: Éditions du Seuil.

Sæbø, K. J. (2009). Judgment ascriptions. Linguistics and Philosophy 32(4), 327-352.

Sassoon, G. W. (2013). Vagueness, Gradability and Typicality. The Interpretation of Adjectives and Nouns. Leiden: Brill.

Sassoon, G. W. (2017). Dimension accessibility as a predictor of morphological gradability. In Y. Winter and J. A. Hampton (Eds.), Compositionality and Concepts in Linguistics and Psychology, pp. 291-326. Amsterdam: Springer.

Stephenson, T. (2007). Judge dependence, epistemic modals, and predicates of personal taste. Linguistics and Philosophy 30(4), 487-525.

Suñer Gratacós, A. (1999). La aposición y otras relaciones de predicación en el sintagma nominal. In I. Bosque and V. Demonte (Eds.), Gramática descriptiva de la lengua española, Volume I, pp. 523-564. Madrid: Espasa Calpe.

de Swart, H., Y. Winter, and J. Zwarts (2007). Bare nominals and reference to capacities. Natural Language \& Linguistic Theory 25(1), 195-222.

Villalba, X. and A. Bartra-Kaufmann (2010). Predicate focus fronting in the spanish determiner phrase. Lingua 120(4), 819-849.

Vinet, M.-T. (1991). French non-verbal exclamative constructions. Probus 3(1), 77-100.

de Vries, H. (2010). Evaluative Degree Modification of Adjectives and Nouns. Master's thesis, U. Utrecht.

de Vries, H. (forthcoming). Gradable nouns as concepts without prototypes. In L. McNally, E. Castroviejo, and G. W. Sassoon (Eds.), The Semantics of Gradability, Vagueness and Scale Structure. Springer.

Zanuttini, R. and P. Portner (2003). Exclamative clauses: At the syntax-semantics interface. Language 79(1), 39-81. 